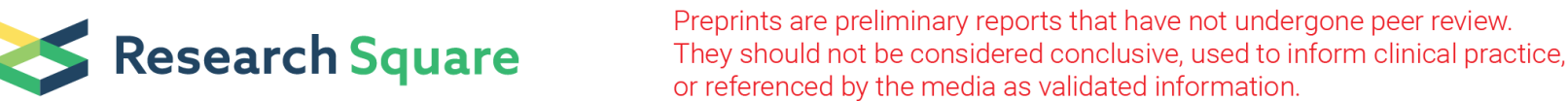

\section{Significance of Early Acidosis in Predicting Early Mortality Among Flame Burned Patients in a Kenyan National Hospital}

Edward Nandi Mackutwa ( $\square$ mackutwa@yahoo.com )

University of Nairobi School of Medicine https://orcid.org/0000-0001-7544-2725

Stanley Ominde Khainga

University of Nairobi School of Medicine

James Muturi Ndung'u

University of Nairobi School of Medicine

Charles Okwemba Anangwe

Kenyatta National Hospital

Research Article

Keywords: flame, burns, acid-base, predictors, mortality

Posted Date: December 21st, 2021

DOI: https://doi.org/10.21203/rs.3.rs-922053/v2

License: (9) This work is licensed under a Creative Commons Attribution 4.0 International License.

Read Full License 


\section{Abstract}

Background: Burn pathophysiology, fluid therapy and mortality have been assessed by various laboratory parameters including lactate and base deficit serum markers. This study targeted flame injured cohort with an objective to determine the significance of early acidosis, through measurement of three acid base indices at admission in predicting 5-day (early) mortality among the flame burned patients.

Methodology: A cohort study. Eighty flame injured patients presenting within 24 hours of incident were assessed for arterial blood $\mathrm{pH}$, lactate and base deficit (BD). Mortality was recorded until day 28. Receiver operating characteristics curves were drawn; area under curve, cut offs, sensitivities and specificities for $\mathrm{BD}$, lactate and $\mathrm{pH}$ were determined for 5-day mortality. The cut offs were used to derive contingency tables for calculation of predictive values. Odds ratios were calculated at $95 \%$ confidence interval. 28 day survival curve was generated. Level of significance was $<0.05$.

Results: 28 -day mortality was $39 \%$. Five-day mortality was $24 \%$. The latter was predicted by a lactate level of $2.36 \mathrm{mmol} / \mathrm{L}$, BD of $-10.05 \mathrm{mmol} / \mathrm{L}$ and $\mathrm{pH}$ of 7.344 with $75 \%, 74 \%$ and $95 \%$ sensitivities respectively. Odds of patients dying at these levels or worse were $6.3,11.4$ and 36.9 respectively all with significant $p$ values.

Conclusion: Arterial pH, base deficit and lactate are good predictors of 5-day mortality among fire victims in the Kenyan context.

\section{Highlights}

- $48 \%$ of fire victims presenting to a Kenyan National Hospital present with significant metabolic acidosis.

- $24 \%$ of the fire casualties died within five days and $39 \%$ of them died within 28 days of hospitalization.

- Arterial lactate, base excess and pH showed a good prediction of early mortality among flame burned patients.

\section{Background}

Burns is a type of trauma that has afflicted man since he first invented the use of fire 1.9 Million years ago (1). Major burns are a significant cause of morbidity and mortality in many hospitals. In one of the national referral hospitals in Kenya, close to 600 major burns patients were admitted annually. Nearly $40 \%$ of these were as a result of open flames out of which $30 \%$ succumbed to their injuries. These fire related deaths accounted for up to $76 \%$ of overall burn mortality (2). Standard initial care included fluid and electrolyte therapy, intubation and oxygen supplementation in suspected inhalational injury and wound care. Alkali therapy was not part of standard of care in acidotic flame burned patients. 
Well known predictors of mortality among the many determinants of burn related deaths are total burn surface area, depth of the burn and presence of inhalational injury as described by J. Tobiasen et al in 1982 (3). These are more severe in flame burns compared to other burn mechanisms and cause greater derangement of physiology which begin soon after the burn incident (2). Key among these are perturbations in body fluids metabolism, peripheral perfusion, gaseous exchange and acute inflammatory response $(4,5)$. The resulting pathophysiology tends to cause acidosis and can be detected by various clinical and laboratory parameters including arterial blood $\mathrm{pH}$, base deficit and lactate levels. These three parameters measured at admission formed the basis of this study. Their significance in predicting 5-day mortality was assessed premised on the fact that such early deaths would more likely be due to primary physiological effects of the burn as opposed to secondary complications such as wound sepsis (6).

\section{Methods}

This was a prospective observational cohort study which was carried out between April 2017 and February 2018. Data collection spanned six months. It involved flame burned patients aged 13 years or older presenting within 24 hours of fire incident to the accident and emergency department of the national referral hospital. All patients received standard of care according to the hospital's protocol. The sample size was determined by Fisher's formula with finite population correction (7). The target population was fire casualties who presented to authors' hospital in half a year. Mortality of these patients from previous studies done at the same centre was reported to be $30 \%$ (2). Therefore, the calculated sample size was 80 participants.

Requisite approvals, including publication of findings, were obtained from the institutional research and ethics committee.

Eligible participants were recruited consecutively as soon as they arrived at the accident and emergency department. Written consent was obtained either from the patients or their next of kin as appropriate. Immediately thereafter, total burn surface area (\%TBSA) was estimated using Lund-Browder chart. Two mililiters of arterial blood was drawn aseptically into heparinized syringe from the radial or femoral artery and submitted to the laboratory within 20 minutes. Among other parameters, three acid base indices of interest (the $\mathrm{pH}$, base deficit and lactate) were measured using Siemens RapidPoint ${ }^{R} 500$ blood gas analysis machine. Mortality within the first 28 days of patients' admission was recorded with special interest of early deaths that occurred within the first 5 days.

Statistical package for social sciences (SPSS) version 23 was used for analysis. Receiver operating characteristic (ROC) curves were generated to determine cut off values and associated sensitivity and specificity for base excess, lactate and $\mathrm{pH}$. The cut offs were used to derive contingency tables with 5-day mortality as the primary outcome. Positive predictive value (PPV), negative predictive value (NPV) and odds ratios (OR) at $95 \%$ confidence interval were calculated. Kaplan Meier survival curve was generated for 28 days' survival. All statistical tests were considered significant at a $p$-value of $<0.05$. 


\section{Results}

\section{Demographics}

Eighty patients were studied; $56 \%$ were males $(n=45)$ and $44 \%(n=35)$ females. Majority $(84 \%)$ aged between 18-45 years [Table 1].

Table 1

Demographic characteristics of the fire casualties

\begin{tabular}{|ll|}
\hline & Frequency $\mathbf{n}(\%)$ \\
\hline Gender & \\
Male & $45(56.3)$ \\
Female & $35(43.7)$ \\
Age Group & \\
\hline$<18$ & $4(5.0)$ \\
$18-25$ & $28(35.0)$ \\
\hline $26-35$ & $27(33.8)$ \\
\hline $36-45$ & $12(15.0)$ \\
\hline$>45$ & $9(11.3)$ \\
\hline
\end{tabular}

\section{Total burn surface area (\%TBSA)}

Cutaneous total burn surface area of the patients ranged from $6-100 \%$ with a median of $25.5 \%$ and a mean of $30.9 \%$ [Table 2]. 
Table 2

Cutaneous total burn surface area

(\%TBSA) of flame burned patients

\begin{tabular}{|ll|}
\hline \%TBSA & Frequency (\%) \\
\hline$<10$ & $3(3.8)$ \\
\hline $10-19$ & $21(26.3)$ \\
$20-29$ & $22(27.5)$ \\
$30-39$ & $18(22.5)$ \\
$40-49$ & $5(6.3)$ \\
$50+$ & $11(13.8)$ \\
\hline Mean (30.9\%) & $\mathbf{8 0}(100.0)$ \\
\hline
\end{tabular}

\section{Arterial blood acid base parameters}

Three arterial blood gas parameters were targeted: the $\mathrm{pH}$, base deficit and lactate. These had a mean of $7.30,-7.87 \mathrm{mmol} / \mathrm{L}$ and $2.91 \mathrm{mmol} / \mathrm{L}$ respectively [Table3]. 
Table 3

Arterial blood gas analysis findings of 3 selected indices

\begin{tabular}{|ll|}
\hline Selected BGA indices & Frequency $\mathbf{n}$ (\%) \\
\hline $\mathbf{p H}$ & $10(12.5)$ \\
\hline$<7.15$ & $7(8.8)$ \\
\hline $7.15-7.24$ & $21(26.3)$ \\
\hline $7.25-7.34$ & $39(48.8)$ \\
\hline $7.35-7.44$ & $3(3.8)$ \\
\hline$>7.45$ & $80(100.0)$ \\
\hline Mean (7.30) & \\
\hline Base Excess (mmol/L) & $5(6.3)$ \\
\hline$>-2.00$ & $26(32.5)$ \\
\hline-6.00 to -2.00 & $23(28.7)$ \\
\hline-10.00 to -6.01 & $26(32.5)$ \\
\hline$\leq-10.01$ & $80(100)$ \\
\hline Mean (-7.87) & \\
\hline Lactate (mmol/L) & $21(53.9)$ \\
\hline $0-1.9$ & $7(17.9)$ \\
\hline 2 to 3.9 & $8(20.5)$ \\
\hline 4 to 5.9 & $3(7.7)$ \\
\hline$\geq 5.9$ & $39(100.0) *$ \\
\hline Mean (2.91) & \\
\hline * A study limitation where only 39 samples of the 80 were tested for lactate levels. \\
\hline
\end{tabular}

The three blood gas parameters were correlated with \%TBSA. All were found to worsen with increasing \%TBSA on Pearson's moment product correlation [Table 4]. 
Table 4

Pearson's moment-product correlation for \%TBSA vs acid base indices

\begin{tabular}{|lll|}
\hline & Pearson's- product correlation with \%TBSA $(r)$ & p-value \\
\hline Arterial base Excess & 0.538 & $<0.001$ \\
\hline Arterial lactate & 0.695 & $<0.001$ \\
\hline Arterial blood pH & -0.588 & $<0.001$ \\
\hline
\end{tabular}

\section{Mortality and survival}

Twenty eight day mortality was found to be $38.8 \%(n=31)$ with the median mortality at day 5 . Twenty three percent $(n=7)$ of all deaths occurred within 24 hours of admission, $61.3 \%(n=19)$ by day 5 and $67.8 \%(n=21)$ by day 7 . Twenty-eight-day mean survival of flame burned patients was $20.81(95 \% \mathrm{Cl}, 1.37$ - 23.50) days [figure 1].

\section{Receiver operating characteristics graphs for 5-day mortality}

Receiver operating characteristics (ROC) graphs for 5-day mortality prediction were drawn for arterial base deficit, lactate and $\mathrm{pH}$. The area under the curve (AUC) was examined for each of the graphs. Cut off values were derived based on sensitivity and specificity for each graph as follows:

\section{Base deficit}

Base deficit (BD) AUC value was $0.80(95 \% \mathrm{Cl}, 0.69-0.91)$ and a cut off value of $-10.05 \mathrm{mmol} / \mathrm{L}$ with sensitivity of $73.7 \%$ and specificity of $80.3 \%(p<0.001)$ hence good in predicting 5 -day mortality [figure 2].

\section{Arterial lactate}

The AUC for arterial lactate was $0.75(95 \% \mathrm{Cl}, 0.56-0.94)$. The cut off was $2.36 \mathrm{mmol} / \mathrm{L}$ with a sensitivity of $75.0 \%$ and specificity of $67.7 \%(p=0.034)$ hence fair in predicting 5 -day mortality [figure 3 ].

\section{Arterial blood pH}

The AUC for blood pH was $0.82(95 \% \mathrm{Cl}, 0.74-0.91)$. The cut off was 7.344 with a sensitivity of $94.7 \%$ and specificity of $67.2 \%(p<0.001)$ hence good in predicting 5 -day mortality [figure 4].

\section{Prediction of 5-day mortality based on cut off values for the three acid base indices}

The cut off values for each of the three acid base indices were used to generate contingency tables. Positive predictive values, negative predictive values and odds ratios were calculated at $95 \%$ confidence 
interval with 5-day mortality as the primary outcome [Table 5].

Table 5

Contingency table for 5-day mortality predicted by the acid base indices' ROC cut offs

\begin{tabular}{|c|c|c|c|c|c|c|}
\hline Acid base parameter & Dead & Alive & Odds ratio ${ }^{a}$ & p-value & PPV $^{b}(\%)$ & $\operatorname{NPV}^{c}(\%)$ \\
\hline \multicolumn{7}{|l|}{$\begin{array}{l}\text { BD cut off } \\
\text { value (mmol/L) }\end{array}$} \\
\hline$\leq-10.05$ & 14 & 12 & & & 53.8 & \\
\hline$>-10.05$ & 5 & 49 & & & & 90.7 \\
\hline \multirow[t]{2}{*}{ Total } & 19 & 61 & 11.4 & $<0.001$ & & \\
\hline & & & $(3.4-37.9)$ & & & \\
\hline \multicolumn{7}{|c|}{ Lactate cut off value (mmol/L) } \\
\hline$\geq 2.36$ & 6 & 10 & & & 37.5 & \\
\hline$<2.36$ & 2 & 21 & & & & 91.3 \\
\hline \multirow[t]{2}{*}{ Total } & 8 & 31 & 6.3 & 0.045 & & \\
\hline & & & $(1.1-36.9)$ & & & \\
\hline \multicolumn{7}{|l|}{$\mathrm{pH}$ cut off value } \\
\hline$\leq 7.344$ & 18 & 20 & & & 47.4 & \\
\hline$>7.344$ & 1 & 41 & & & & 97.6 \\
\hline \multirow[t]{2}{*}{ Total } & 19 & 61 & 36.9 & $<0.001$ & & \\
\hline & & & $(4.6-296.4)$ & & & \\
\hline \multicolumn{7}{|c|}{ a Odds ratio was calculated at 95\% confidence interval and level of significance pegged at $<0.05$. } \\
\hline \multicolumn{7}{|c|}{ bPPV- positive predictive value. } \\
\hline
\end{tabular}

\section{Discussion}

Burn injury induces complex physiological stress to the victim and untold anguish. Many determinants of burn mortality have been studied and include extremes of age, presence of comorbid conditions and inadequate or delayed resuscitation $(8,9)$. However, strong determinants of burn mortality are \%TBSA, depth of the burn and presence of inhalational injury (3). The resulting burn pathophysiology lead to derangements in fluid metabolism, circulatory and respiratory perturbations, systemic inflammatory and metabolic responses. These alterations are worse in fire injuries due to greater thermal energy transfer 
and the potential for inhalational injury. These account for many deaths in fire victims which tend to occur at the scene of incident or in early course of hospitalization compared to deaths from other burn mechanisms $(6,10)$.

The burned skin loses its fluid conservation quality resulting in transdermal exudation of fluid and electrolytes (11). Moreover, blood vessels in the burned tissue suffer endothelial necrosis and breakdown causing further fluid and even blood loss (12). Thirdly, the burn injury initiates acute inflammatory process locally which is associated with vasodilation, increased vascular permeability and thereby third spacing of body fluids. The locally released cytokines may lead to systemic inflammatory response syndrome (SIRS). Furthermore, catecholamine surge due to the injury causes vasoconstriction that increases total peripheral resistance (13). These factors lead to contracted vascular volume and reduced perfusion resulting into hypovolemic and redistributive shock of various degrees. A reduction of oxygen tension in tissues and accumulation of metabolic waste in the interstitial fluid follows. If present, physicochemical inhalation injury to the respiratory epithelium leads to ventilation-perfusion mismatch which worsens hypoxemia. Besides, should there be asphyxiants such as carbon monoxide in the inhaled smoke, further hypoxemia results. These perfusion, inflammatory and respiratory disturbances lead to metabolic derangements including acidosis which was the target for this study.

The basic burns profile and mortality findings in this study were similar to prior studies carried out at the same institution involving the flame injured cohort. The mean \%TBSA was 30.9\%. Overall 28-day mortality was $38.8 \%$. Sixty-one percent of the deaths occurred within the first five days and additional $7 \%$ occurring by day 7 of admission.

All the three acid base indices taken at admission were noted to worsen with increasing \%TBSA indicating worsening pathophysiology. At derived cut offs, odds of early (5-day) mortality were significantly high.

Base deficit was found to be a good predictor of 5-day mortality at cut off value of $-10.05 \mathrm{mmol} / \mathrm{L}$ $(p<0.001)$ with odds ratio of $11.4(95 \% \mathrm{Cl}, 3.4-37.9)$. Choi et al reported that abnormal increase in BD ( $<-6$ $\mathrm{mmol} / \mathrm{L}$ ) after a burn injury represents mal-perfusion state which may not be recognized by traditional parameters such as urine output (5). Mutschler et al lent credence to this observation asserting that BD increases with deepening degrees of hypovolemic shock in trauma patients. He noted that a BD of $\leq$ $-10 \mathrm{mmol} / \mathrm{L}$ represented a class IV hypovolemic shock (14). Choi et al reported that patients with a BD of < $-6 \mathrm{mmol} / \mathrm{L}$ recorded within 24 hours of a burn injury had a more florid SIRS, were more prone to acute respiratory distress syndrome and experienced more severe multiple organ dysfunction syndrome hence a higher mortality outcome compared to those with BD of $>-6 \mathrm{mmol} / \mathrm{L}$ (5). Our study echoed Choi's and Mutschler's finding such that a BD of $-10.05 \mathrm{mmol} / \mathrm{L}$ predicted mortality with a sensitivity of $73.7 \%$ and specificity of $80.3 \%$.

Cochran et al reported that an early rise in serum lactate was an independent risk factor for death after a burn injury (15). This was demonstrable in our study where at $2.36 \mathrm{mmol} / \mathrm{L}$ or more, lactate showed an acceptable discrimination for 5-day mortality with 6.3 times more likelihood of death compared to 
patients with $<2.36 \mathrm{mmol} / \mathrm{L}(95 \% \mathrm{Cl}, 1.1-36.9)$. Therefore, just as $\mathrm{BD}$, lactate elevations at day 0 is a useful parameter to separate survivors from non survivors of burns a position also observed by Andel et al (16).

The $\mathrm{BD}$ and lactate lower the blood $\mathrm{pH}$. A pH of 7.344 or less predicted early mortality with a sensitivity of $94.7 \%$ and specificity of $67.2 \%$ ( $p<0.001$ ). The odds of burn patients dying at these levels was 36.9 times more than those with a higher $\mathrm{pH}(95 \% \mathrm{Cl}, 4.6-296.4)$. A higher $\mathrm{pH}$ predicted 5-day survival of up to $97.6 \%$.

From the foregoing, the three acid base parameters discussed can be utilized to identify burned patients at higher risk of death. Additionally, literature highlights importance of lactate and BD in particular, in estimating fluid requirement and adequacy of resuscitation in major burns. However, except for the work by Peaston, in 1968 there is paucity of data on the utility of alkali therapy in treatment of acidosis in burns as applied to other causes of severe acidosis $(14,16,17,18)$. Therefore, whether or not alkali therapy can help better outcomes in severe acidosis associated with flame burns is a potential area of further study.

\section{Conclusion}

Flame burned patients undergo complex pathophysiological processes that explain the tendency for an elevated arterial blood base deficit (BD), a raised lactate and a lower $\mathrm{pH}$. Measured at admission, these parameters can predict five-day mortality with good sensitivity and high odds of death at cut offs of $-10.05 \mathrm{mmol} / \mathrm{L}, 2.36 \mathrm{mmol} / \mathrm{L}$ and 7.344 respectively. Therefore, these tests can help identify early, burned patients at higher risk of death and help inform and guide a more vigorous early resuscitation and enhanced treatment. Moreover, it is plausible to deduce that alkali treatment may be a useful addition to the resuscitation therapy administered to selected burns patients that present with severe acidosis.

\section{Study Limitation}

Only 39 of the 80 recruited participants had their samples tested for lactate due to frequently unavailable reagent for lactate measurement at the study hospital. None the less, the results and analysis obtained were significant and therefore included in this article.

\section{Recommendations}

Findings of this study may be used to identify physiologically high risk flame injured patients for a more aggressive fluid therapy and enhanced treatment. A question worth further research is whether alkali therapy may have a useful role in burn related severe acidosis.

\section{Abbreviations}

BD: Base deficit; TBSA: Total burn surface area; PPV: Positive predictive value; NPV: Negative Predictive value; OR: Odds ratio; ROC: Receiver operating characteristics; AUC: Area under the curve; Cl: Confidence 
interval; SIRS: Systemic inflammatory response syndrome.

\section{Declarations}

\section{Acknowledgement}

Wycliffe Ayieko of School of Public Health, University of Nairobi is acknowledged for data analysis and Ms Esther Kimaru, an accident and emergency care nurse at Kenyatta National Hospital, is acknowledged for assistance in data collection.

\section{Funding}

This research did not receive any specific financial or non-financial grant from funding agencies in the public, commercial or not for profit sectors.

\section{Authors' contribution}

ENM was the principal investigator, drafted the manuscript and is the Corresponding author.

SOK did the concept paper and edited the draft manuscript.

JMN reviewed literature and did the second manuscript.

COA helped interpret and contextualise the laboratory data and typeset the final draft of the manuscript.

\section{Availability of data and materials}

The data set for this study is available on reasonable request to the corresponding author.

\section{Competing interests}

Authors declare that they have no competing interests.

\section{Ethics and consent to participate}

The joint Kenyatta National Hospital and University of Nairobi Ethics and Research Committee's approval was obtained to carry out the study and to publish the results under reference number P744/10/2016.

\section{Consent of publication}

All data was anonymised. None the less, consent to publish the data was obtained from each participant at the point of enrolling into the study.

\section{References}


1. Gowlet J.A.J. The Discovery of Fire by Humans; A Long and Convoluted Process. Phil Trans. R. Soc B 371: 20150164.

2. Nthumba P, Oliech J.S. Outcome of Moderate to Severe Burns at Kenyatta National Hospital. East Centr Afr J Surg. 2005;10(2): 37-42.

3. Tobiasen J, Hiebert JM, Edlich R. The abbreviated Burn Severity Index. Ann Emerg Med. 1982;11(5): 260-262.

4. Tan Chor Lip H, Tan JH, Thomas M, et al. Survival analysis and mortality predictors of hospitalized severe burn victims in a Malaysian burns intensive care unit. Burns \& trauma. 2019 Dec 1;7.

5. Choi J, Gomez M, Fish JS, et al. The Relevance of Base Deficits Following Burn Injury: 20. Journal of Burn Care \& Research. 2000 Jan 1;21:S144.

6. Church D, Elsayed S, Reid O, et al. Burn wound infections. Clinical microbiology reviews. $2006 \mathrm{Apr}$ 1;19(2):403-34.

7. Daniel WW. Biostatistics: A Foundation for Analysis in the Health Sciences. 7th edn. New York: John Wiley \& Sons; 1999.

8. Santos DC, Barros F, Gomes N, et al. The effect of comorbidities and complications on the mortality of burned patients. Annals of burns and fire disasters. 2017 Jun 30;30(2):103.

9. Gore DC, Hawkins HK, Chinkes DL, et al. Assessment of adverse events in the demise of pediatric burn patients. Journal of Trauma and Acute Care Surgery. 2007 Oct 1;63(4):814-8.

10. Swanson JW, Otto AM, Gibran NS, et al. Trajectories to death in patients with burn injury. J Trauma Acute Care Surg; 2013;74(1):282-8.

11. Namdar T, Stollwerk PL, Stang FH, et al. Transdermal fluid Loss in Severely Burned Patients. Ger Med Sci. 2010;8Doc28.

12. Vinay K, Abul KA, Nelson F. (Eds). Robbins and Cotran Pathologic Basis of Disease. 7th edn. India: Elsevier; 2004:49-75pp.

13. Kulp GA, Herndon DN, Suman E, et al. Extent and Magnitude of Catecholamine Surge in Pediatric Burned Patients. Shock; 2010;33(4): 369-374.

14. Mutschler M, Nienaber $U$, Brockamp T, et al. Renaissance of base deficit for the initial assessment of trauma patients: a base deficit-based classification for hypovolemic shock developed on data from 16,305 patients derived from the Trauma Register DGU. Critical Care. 2013;17(2): R42.

15. Cochran A, Edelman LS, Saffle JR, et al. The relationship of serum lactate and base deficit in burn patients to mortality. Journal of burn care \& research. 2007 Mar 1;28(2):231-40.

16. Andel D, Kamolz LP, Roka J, et al. Base deficit and lactate: early predictors of morbidity and mortality in patients with burns. Burns. 2007 Dec 1;33(8):973-8.

17. Peaston MJ. Metabolic Acidosis in Burns. BMJ; 1968; 30:1 (5595): 809-811

18. Krista L, James W, William J. Base Deficit as an Indicator of Resuscitation Needs in Patients with Burn Injuries. J Burn Care Rehabil; 1998; 19:4. 
Figures

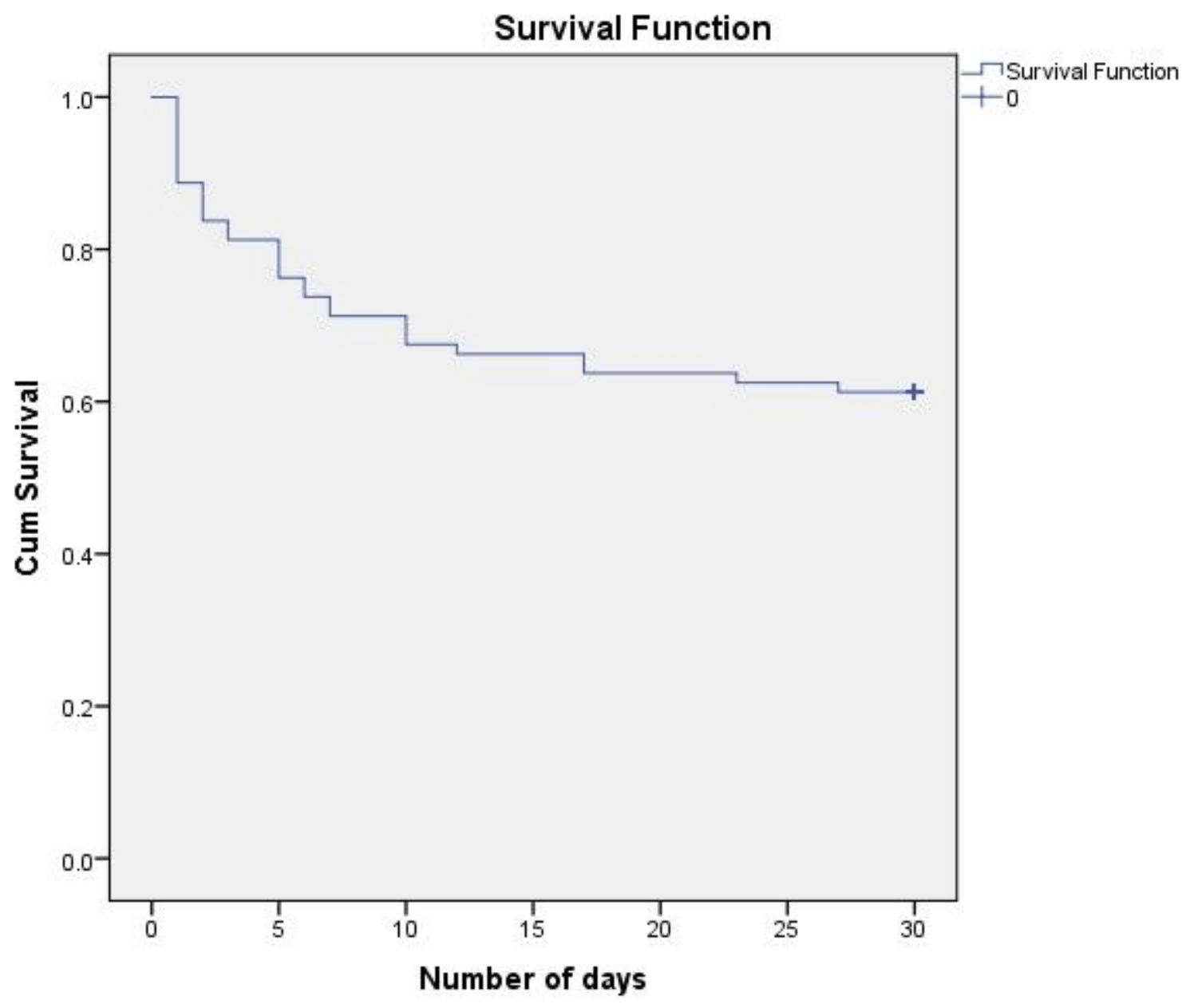

Figure 1

28-day Kaplan Meier survival curve for the flame burned patients 


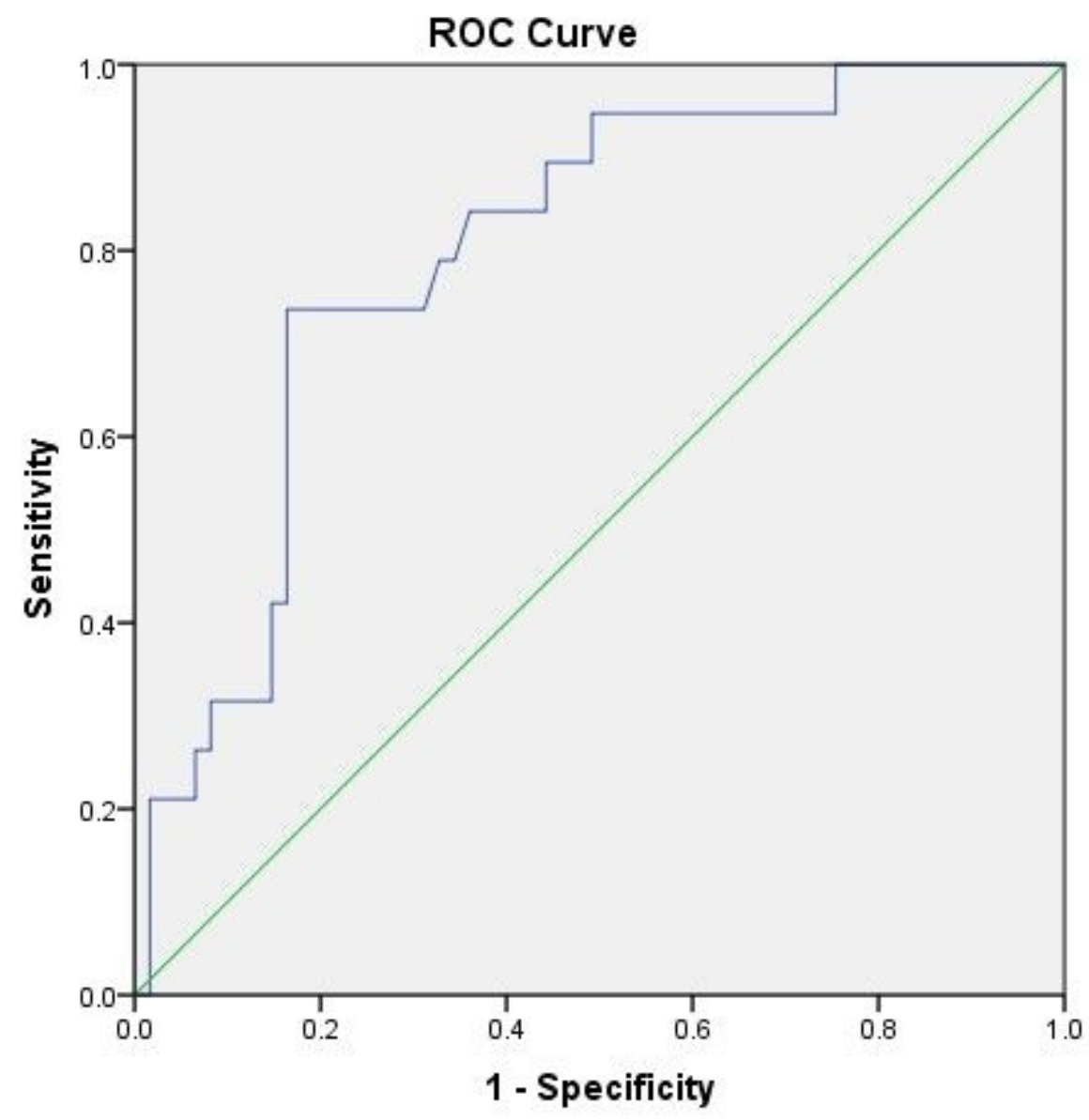

Diagonal segments are produced by ties.

Figure 2

ROC curve for arterial base excess ( $\mathrm{mmol} / \mathrm{L}$ ) vs 5-day mortality 


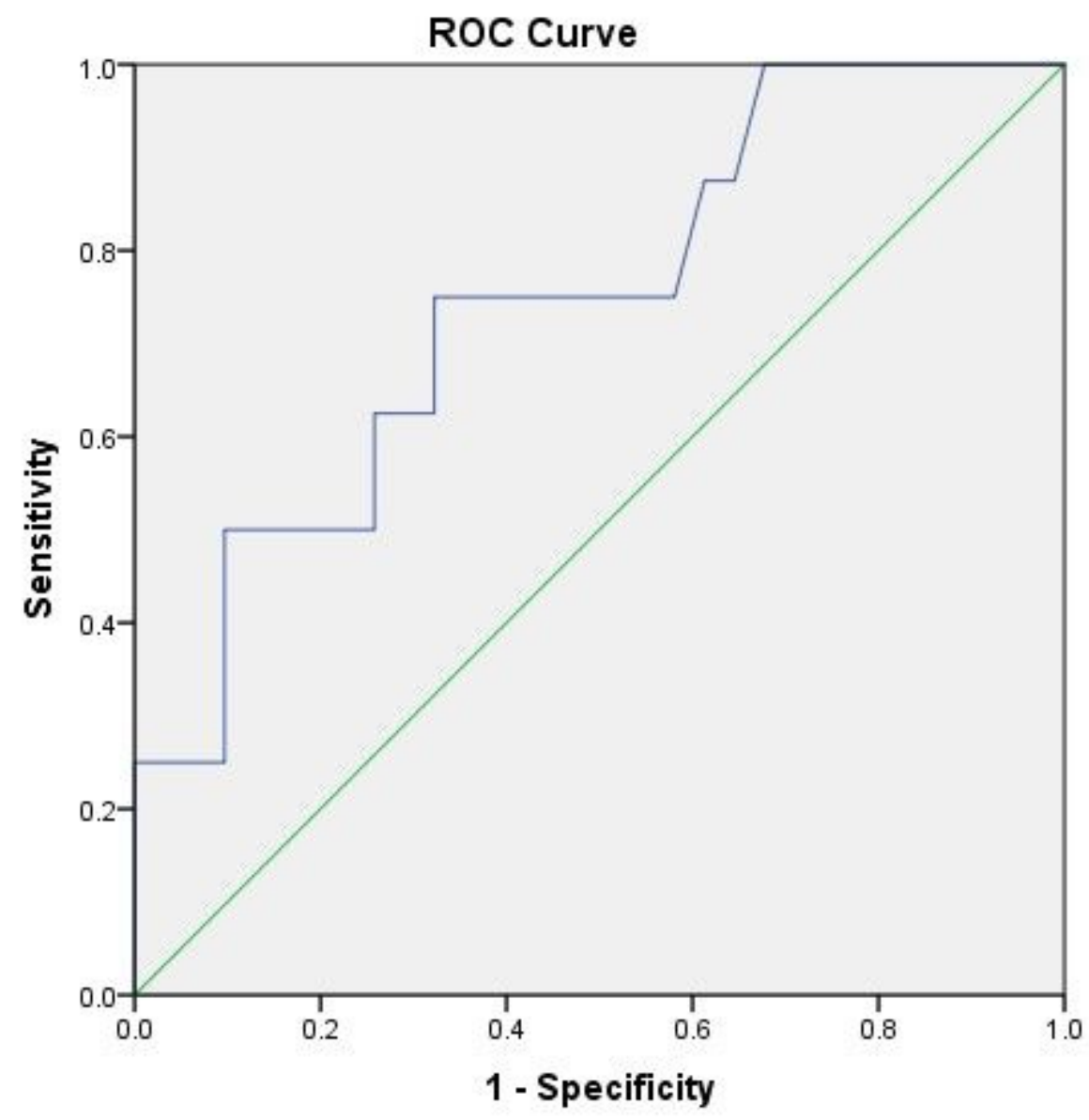

Diagonal segments are produced by ties.

Figure 3

ROC curve for arterial lactate ( $\mathrm{mmol} / \mathrm{L})$ vs 5-day mortality 


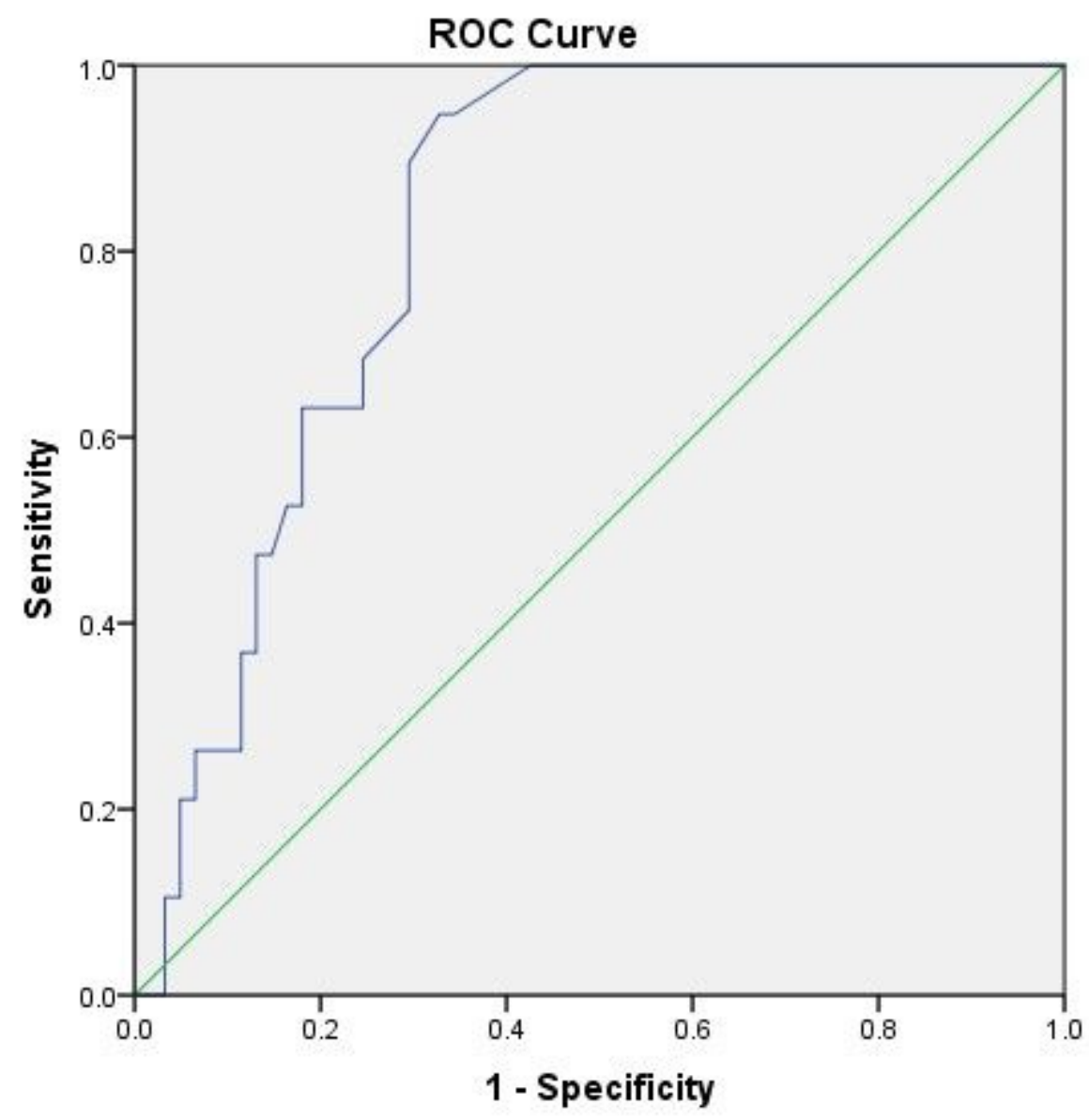

Diagonal segments are produced by ties.

Figure 4

ROC curve for arterial blood pH vs 5-day mortality 